\title{
What do parents expect antenatally and do babies teach them?
}

\author{
E Delight, J Goodall, P W Jones
}

\begin{abstract}
Antenatal inquiry of 658 parents in the North Staffordshire District Health Authority showed at least $13 \%$ to lack knowledge about a baby's potential for personal interaction when under 1 week old. Mothers and fathers varied significantly, independent of parity. Experienced parents expected later smiles. Two hundred and seventy eight of the same families were questioned three to four months after birth. Most parents had observed their baby's early responsiveness. Specific responses (looking, listening) were noted earlier when anticipated and looked for. Significant among postnatal non-responders was their antenatal selection of predominantly impersonal stimulation for a baby. The greatest degree of warmth noted in postnatal observations correlated notably with a father's antenatal interest and postnatal support from him and their friends, a mother's commitment to breast feeding and her knowledge that a very young baby can see, likes faces, and cries for emotional reasons. This highlights areas for antenatal tuition and postnatal encouragement, aiming to enhance warm early mutual regard between parents and child.
\end{abstract}

Research on normal full term babies over the past two decades indicates how soon they show responses along all sensory pathways. ${ }^{1}$ Visually, the preferred pattern from day one is a face, particularly the eyes and brow. The optimal focal distance is that between an admiring face and the baby's when a child is held in the crook of the admirer's arm. Responsive interaction accelerates the baby's identification of key people. $^{2-4}$ There can be a form of smiling from the first day with clearly responsive smiles by 2 to 4 weeks of age. ${ }^{5}$ Imitative behaviour has been noted by 3 days $^{6}$ and recognition of the mother by smell within a week. ${ }^{7}$ Though some babies, like adults, express themselves more readily than others, the infant appears to be innately disposed to respond to human more than mechanical qualities and can be the one to initiate communication with a consistent care giver. ${ }^{8}$

Work on the father-infant relationship has until recently been neglected. A father's preliminary engrossment at the time of birth does not exclude the risk of paternal alienation later on unless his continued involvement is encouraged. ${ }^{9}$ Researchers now recognise all this, paediatricians are learning it with interest, but to what extent do parents recognise the competence of their own babies?
The aims of the study were to determine whether fathers and mothers have different expectations about a newborn baby's responsiveness, whether these are correct, whether previous experience of babies alters them, and whether (and what) a baby later teaches parents. This could affect both antenatal instruction and postnatal reinforcement. To enhance parentbaby interaction encourages the growth of warm parental understanding which then should forestall deprivation and abuse.

\section{Subjects and methods}

In 1987-8, 416 mothers and 242 of their partners separately answered structured questionnaires issued in two specified weekly antenatal clinics of the North Staffordshire Maternity Hospital, Stoke on Trent, the goal being to assess at least 200 primiparous and 200 multiparous women and their partners. The questionnaire was given to willing mothers of 18 years old or more whose partners (in person or via the mothers) were offered a questionnaire. Both documents were to be completed at once or posted back. There were 214 first time mothers, 125 first time fathers, 202 multiparous mothers, and 115 experienced fathers. The status of two fathers was unrecorded. Twenty one percent of the fathers came from socioeconomic groups I/II, $49 \%$ from group III, and $18.5 \%$ from groups IV/V, $11 \cdot 5 \%$ being unknown or unemployed.

Parents were identified by name and three to four months after the birth were sent a prepaid, postal, open ended questionnaire. Because of the poor response to the fathers' antenatal questionnaire and to encourage discussion about their baby this was a shared exercise. Altogether 278 of the original 416 families responded and their personal antenatal and postnatal results were compared and contrasted. Although not all parents answered each question, enough did so to make comparisons valid. Relevant numbers appear in the text.

The $P$ score $(0-3)$ was gauged postnatally and recorded the degree of paternal involvement indicated by a father's presence at the birth, by spontaneous reference to him in answer to two questions about the mother's preferred advisers and actual supporters, and two other questions about the baby's selective responsiveness to faces and voices. Any extra mention of the father gained a sixth mark, two marks then contributing one point for the final $P$ score. The $R R$ score (1-3), also postnatal, attempted to determine reciprocal regard between parents and baby and indicated the means by which 
firm two way attachment was growing. It was cumulatively scored, with points given for mention of the baby's personal as well as physical needs, the parents' recollection of the child's personally interactive behaviour, and the overall warmth of their answers. Original continuous data from 278 responsive families was categorised into the three grades, approximately equal numbers being allocated to each. (Independent evaluation by ED and JG agreed, small variations in raw scores leaving the final $R R$ grade unaffected.)

\section{STATISTICAL ANALYSIS}

Yes/no answers were tabulated as percentages and subgroups compared by age, education, socioeconomic group, first or subsequent baby, and father/mother. Small subgroups of mothers were compared on the variables of parity, age, and education.

The tables give total numbers in each parent group, but to exclude bias by collusion antenatal fathers and mothers were compared by paired tests. The $\chi^{2}$ test of association in categorical data and in some cases Fisher's exact test were used. The sign test was used to compare paired ordinal data. Standard normal values, corrected for continuity, were employed to test difference between proportions where the sample sizes were large. Tests between groups of continuous measurements were based on the percentage points of the standard normal, Student's $t$, and F distributions. Most of the analyses were carried out using the NCSS statistical package. ${ }^{10}$

Table 1 Maternal and paternal background and expectations by age

\begin{tabular}{|c|c|c|c|c|c|c|}
\hline \multirow[b]{2}{*}{$\begin{array}{l}\text { Category } \\
\text { (\% who would have:) }\end{array}$} & \multicolumn{3}{|c|}{ Age of mother (years) } & \multicolumn{3}{|c|}{ Age of father (years) } \\
\hline & $\begin{array}{l}<22 \\
(n=94)\end{array}$ & $\begin{array}{l}22-29 \\
(n=225)\end{array}$ & $\begin{array}{l}>29 \\
(n=97)\end{array}$ & $\begin{array}{l}<24 \\
(n=46)\end{array}$ & $\begin{array}{l}24-31 \\
(n=130)\end{array}$ & $\begin{array}{l}>31 \\
(n=65)\end{array}$ \\
\hline $\begin{array}{l}\text { First baby } \\
\text { Left school }<17 \text { years } \\
\text { Intended to breast feed } \\
\text { Asked information of parents } \\
\text { Asked information of professionals } \\
\text { Expected help from parents } \\
\text { Expected help from professionals } \\
\text { Expected help from peers } \\
\text { Expected help from partner } \\
\text { Attended antenatal classes } \\
\text { Learnt about child care at school } \\
\text { Learnt about child development } \\
\text { Post-school training in childcare } \\
\text { Held a baby } \\
\text { Changed a nappy } \\
\text { Read hospital literature }\end{array}$ & $\begin{array}{r}70 \\
90 \\
34 \\
69 \\
24 \\
65 \\
14 \\
7 \\
50 \\
54 \\
56 \\
51 \\
9 \\
98 \\
90 \\
93\end{array}$ & $\begin{array}{r}50 \\
41 \\
54 \\
50 \\
38 \\
47 \\
24 \\
8 \\
52 \\
54 \\
36 \\
25 \\
8 \\
98 \\
80 \\
93\end{array}$ & $\begin{array}{r}35 \\
70 \\
79 \\
35 \\
38 \\
41 \\
21 \\
8 \\
58 \\
58 \\
15 \\
9 \\
6 \\
97 \\
82 \\
89\end{array}$ & $\begin{array}{r}71 \\
43 \\
62 \\
47 \\
5 \\
42 \\
8 \\
11 \\
12 \\
4 \\
10 \\
0 \\
42 \\
12 \\
78\end{array}$ & $\begin{array}{r}51 \\
101 \\
68 \\
27 \\
12 \\
38 \\
11 \\
6 \\
19 \\
2 \\
8 \\
22 \\
56 \\
19 \\
69\end{array}$ & $\begin{array}{r}38 \\
44 \\
69 \\
31 \\
10 \\
30 \\
18 \\
4 \\
-24 \\
3 \\
4 \\
18 \\
57 \\
24 \\
78\end{array}$ \\
\hline
\end{tabular}

Table 2 Major areas of antenatal parental ignorance about a baby's abilities

\begin{tabular}{|c|c|c|c|c|c|}
\hline Parent believes that: & No $(\%)$ mothers & No (\%) fathers & p Value & $\begin{array}{l}\text { No of } \\
\text { paired data }\end{array}$ & $\begin{array}{l}\chi^{2} \\
(1 d f)\end{array}$ \\
\hline $\begin{array}{l}\text { At birth: } \\
\text { Not at all responsive } \\
\text { No response to talk } \\
\text { No visual response to shapes } \\
\text { No visual response to faces }\end{array}$ & $\begin{array}{l}223 / 381(58 \cdot 5) \\
106 / 416(25 \cdot 5) \\
118 / 408(28 \cdot 9) \\
136 / 410(33 \cdot 2)\end{array}$ & $\begin{array}{r}159 / 211(75 \cdot 4) \\
85 / 238(35 \cdot 7) \\
45 / 239(18 \cdot 8) \\
103 / 239(43 \cdot 1)\end{array}$ & $\begin{array}{l}<0.001 \\
<0.001 \\
<0.001 \\
<0.001\end{array}$ & $\begin{array}{l}202 \\
238 \\
235 \\
237\end{array}$ & $\begin{array}{l}14 \cdot 66 \\
15 \cdot 73 \\
12 \cdot 70 \\
16 \cdot 05\end{array}$ \\
\hline $\begin{array}{l}\text { At one week: } \\
\text { Not enjoying talk } \\
\text { Not enjoying shapes or faces }\end{array}$ & $\begin{array}{l}56 / 416(13 \cdot 5) \\
54 / 407(13 \cdot 3)\end{array}$ & $\begin{array}{l}49 / 238(20 \cdot 6) \\
31 / 237(13 \cdot 1)\end{array}$ & $\begin{array}{l}\text { NS } \\
\text { NS }\end{array}$ & & \\
\hline $\begin{array}{l}\text { Up to } 3 \text { months: } \\
\text { Not yet learning }\end{array}$ & $64 / 415(15 \cdot 4)$ & $48 / 238(20 \cdot 2)$ & NS & & \\
\hline $\begin{array}{l}\text { At } 3 \text { months: } \\
\text { Cries because naughty }\end{array}$ & $54 / 414(13.0)$ & $30 / 241(12 \cdot 4)$ & NS & & \\
\hline
\end{tabular}

\section{Results}

\section{ANTENATAL INQUIRY}

Past experience and general expectations (table 1) Particularly when young or less well educated, more mothers than fathers had learned about child care or development at school. Attendance at antenatal classes was higher among mothers, though a little more likely among fathers from socioeconomic groups I/II (22\%) than those in groups III $(18 \%)$ or IV/V (17\%). Women were more likely than men to expect help from professionals. Both, particularly when young, tended to ask information of their own parents. However, more fathers in socioeconomic groups I/II (25\%) expected professional help than in groups III $(8 \%)$ or IV/V (9\%) with a reversal of this trend $(24 \%, 33 \%, 40 \%)$ among those seeking advice from their own parents. More multiparous $(67 \%)$ than primiparous $(51 \%)$ women anticipated major help with the baby from their partners. Over half the parents studied said that television had given helpful information about babies. More fathers under 30 years wanted their baby to be breast fed than did mothers. Intent to breast feed was found more in better educated women than in early school leavers $(73 \%, 51 \%)$ and in those from socioeconomic groups I/II more than III or IV/V (77\%, 54\%, 49\%).

\section{Differences between mothers and fathers for levels of antenatal ignorance and experience}

Responsiveness-The word response conjured up different images but the mean (SD) maternal value of a baby's first response was $28 \cdot 6(45 \cdot 5)$ days and that of fathers was $47 \cdot 7(66 \cdot 5)$ days, paired difference in mean $24 \cdot 0$ days: $Z=4 \cdot 93$, $p<0.001(n=201)$.

Most parents gave many appropriate answers about the timing of specific responses, by the end of the first week correctly expecting their baby to be learning (over 50\%), listening to voices (over $80 \%$ ), and reacting to sound (almost 100\%). Others showed considerable ignorance about neonatal responsiveness; mothers and fathers varied significantly but at least $13 \%$ of both partners held serious misconceptions, chiefly about babies of up to a week old (table 2).

Experience-The only significant difference brought about by experience (corrected for continuity) was the expected onset of smiling. Overall $47 \cdot 9 \%(312 / 652)$ parents expected responsive smiles by 6 weeks. When considering 4 weeks as an alternative, inexperienced parents (mothers 16.8\%, 36/214; fathers $22 \cdot 0 \%$, 27/123) more than experienced ones (mothers $8 \cdot 0 \%$, $16 / 200$; fathers $10 \cdot 6 \%, 12 / 113$ ), expected smiles by then: $Z=2.56$ (mothers); $2 \cdot 17$ (fathers), $\mathrm{p}<0.05$.

\section{POSTNATAL INQUIRY}

Responsiveness - Thirty percent of parents noted general responsiveness within a week, the mean time for observation of specific responses (visual, auditory, smiling) being later (table 3). Matching a couple's antenatal and postnatal 
Table 3 Baby's postnatal responses first observed by parents

\begin{tabular}{llll}
\hline & $\begin{array}{l}\text { Mean }(S D) \\
(\text { weeks })\end{array}$ & Median & Quartiles \\
\hline Used eyes & $2 \cdot 90(2 \cdot 49)$ & 3 & 1,4 \\
Enjoyed talk & $2 \cdot 85(2 \cdot 86)$ & 2 & 0,4 \\
Smiled responsively & $4.43(2 \cdot 06)$ & 4 & 3,6 \\
\hline
\end{tabular}

answers, there was a significant association between the postnatal recognition within a week of a baby's visual alertness and attentiveness to talk and mothers who had expected this antenatally: for visual interest, $\chi^{2} 1 \mathrm{df}=9 \cdot 88$, $\mathrm{p}<0.005(\mathrm{n}=261)$ and for interest in talk, $\chi^{2}$ $1 \mathrm{df}=10.61, \mathrm{p}<0.001(\mathrm{n}=274)$.

Smiling-The observed onset ranged from birth to 12 weeks, the mean (SD) of $4.43(2.06)$ weeks differing significantly from the average 6 weeks expected by parents antenatally: $Z=-12 \cdot 70$, $\mathrm{p}<0.001(\mathrm{n}=277)$

Crying babies-Parents antenatally had selected causes of crying from a list; postnatally they made their own speculations. Antenatally and postnatally $100 \%$ of parents thought that babies cry for physical reasons such as hunger. Antenatally $86 \cdot 8 \%(360 / 415)$ of parents but only $77 \cdot 3 \%(214 / 277)$ of parents postnatally indicated emotional causes for crying, such as loneliness or boredom. This was a significant change (using the McNemar test: $\chi^{2} 1 \mathrm{df}=13.43$, $\mathrm{p}<0.001$ )

Parents were more likely to indicate postnatally that their babies cried for emotional reasons when the mothers had been better educated $(45 / 51,88.2 \%)$ than when they had left school at 16 years $(169 / 226,74 \cdot 8 \%) ; \chi^{2}$ $1 \mathrm{df}=4.29, \mathrm{p}<0.05$. Despite these differences, $96 \cdot 8 \%(269 / 278)$ of all parents postnatally would try to comfort a baby by emotionally directed methods such as cuddling or talking. One father still thought postnatally that his 3 month old baby cried because 'naughty'.

Parental warmth and how to gauge it This was attempted by evaluating $P$ and $R R$ scores.

Paternal interest and involvement: $P$ scores Antenatal-Although many mothers included information about their partners, only $58 \cdot 2 \%$ fathers completed the antenatal questionnaire; $18.6 \%(77 / 413)$ fathers attended antenatal classes; $89 \cdot 5 \%$ (365/408) wanted to be present at the birth and $90 \%(244 / 271)$ achieved this. One died and 10 left during the pregnancy.

Postnatal-P scores for 278 fathers ranged from $\mathrm{P0}$ for $4 \%$ (now no contact), P1 for $8 \%, \mathrm{P} 2$ for $16 \%$, and $\mathrm{P3}$ for $72 \% ; 88.5 \%$ men who scored P3 had been at the birth.

\section{Reciprocal regard: $R R$ scores}

Understandably, the warmth with which parents spoke about their baby's personal interest was more noticeable in postnatal than in antenatal replies. A few examples will illustrate this.
Recollections-personal and impersonal:

Q: 'What did your baby like looking at when he/she could first see?'

A: 'My face'. 'Brightly coloured objects'.

Q: 'What does he/she like looking at now?'

A: 'Mum, dad, brother', 'TV'.

Q: 'What does he/she like listening to now?'

A: 'Noises made by mouth', 'Hoover'.

$\mathrm{Q}:$ 'What does he/she like best?'

A: 'Our singing to him', 'Bottle and dummy'. Warmth

Q: 'What do you find most interesting about your baby?'

A: (Original prose) 'The way he sences someone coming into the room, for example, Dad coming home'. 'The delight shown on his face every time he see's me'. 'Everythink'.

Pointers to degree of reciprocal regard

Crying mothers-38.5\% (107/278) of mothers postnatally admitted to crying when their babies cried. This was not related to age, parity, socioeconomic group, or education. Altogether $63.6 \%(68 / 107)$ who cried were breast feeding mothers as against $46 \cdot 5 \%(79 / 171)$ breast feeders in the non-crying group: $Z=2 \cdot 70, p<0 \cdot 01$. Overall, $88.8 \%(246 / 277)$ mothers knew that babies cry for emotional reasons; $91 \cdot 5 \%(97 / 106)$ of those who cried with their babies knew this as did $87 \cdot 1 \%(149 / 171)$ who did not cry with them (this was not significant). Crying mothers tended to have higher RR scores (table 5b).

Some of the parents' replies could have reflected inarticulacy as much as lack of imagination or interest, so RR scores were compared between mothers who left school early or later and between families of different social backgrounds. This showed significant differences.

Reciprocal regard and education-All 95 mothers scoring RR3 breast fed their babies. As intent to breast feed had been associated with higher education, the distribution of RR 1-3 was compared between 227 mothers who left school early and 51 who stayed on after 17 years of age. RR scores were found to be significantly associated with the length of school attendance. In mothers who left school under 17 years $36.6 \%$ scored RR1, 33.9\% RR2, and 29.5\% RR3. In mothers who left school after 17 years $15 \cdot 7 \%$ scored RR1, 29.4\% RR2, and 54.9\% RR3 ( $\chi^{2}$ $2 \mathrm{df}=13.65 ; \mathrm{p}<0.005$ )

Reciprocal regard and socioeconomic groupThirty three fathers were either unemployed or of unknown occupation. In the other 245 families there was a significant association between the decrease in percentage of those scoring RR3 and their descent in social status: $\chi^{2} 4 \mathrm{df}=20 \cdot 19, \mathrm{p}<0 \cdot 001$ (table 4).

Table 4 Reciprocal regard $(R R)$ scores and socioeconomic background. Results are number (\%)

\begin{tabular}{|c|c|c|c|c|}
\hline $\begin{array}{l}\text { Socioeconomic } \\
\text { group }\end{array}$ & $R R I$ & $R R 2$ & $R R 3$ & Total \\
\hline $\begin{array}{l}\text { I/II } \\
\text { III } \\
\text { IV/V }\end{array}$ & $\begin{array}{rr}12 & (4 \cdot 9) \\
37 & (15 \cdot 1) \\
24 & (9 \cdot 8)\end{array}$ & $\begin{array}{cc}19 & (7 \cdot 8) \\
51 & (20 \cdot 8) \\
12 & (4 \cdot 9)\end{array}$ & $\begin{array}{rr}33 & (13 \cdot 5) \\
48 & (19 \cdot 6) \\
9 & (3 \cdot 7)\end{array}$ & $\begin{aligned} 64 & (26 \cdot 1) \\
136 & (55 \cdot 5) \\
45 & (18 \cdot 4)\end{aligned}$ \\
\hline Total & $73(29 \cdot 8)$ & $82(33.5)$ & $90(36 \cdot 7)$ & $245(100)$ \\
\hline
\end{tabular}


Table 5 Pointers to warmth of reciprocal regard ( $R R$ scores)

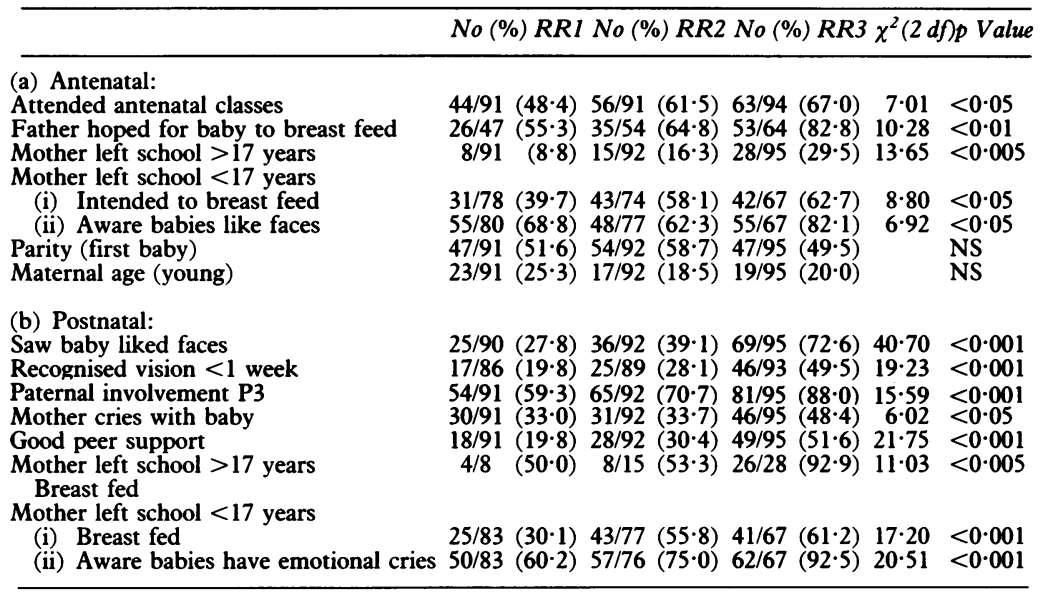

Other significant associations-Including a separate analysis of mothers who left school before 17 years of age and a retrospective antenatal analysis, other significant associations are documented in table 5. Parity and maternal age were not significant.

Non-responders-One hundred and thirty seven of 138 couples who had completed antenatal but not postnatal questionnaires were retrospectively analysed. There was no association with age, sex, previous parity, socioeconomic group, or education, but mothers and fathers differed.

Mothers-Altogether $65 \cdot 5 \%$ (182/278) responders but only $48 \cdot 9 \%$ (67/137) non-responders planned to help a baby to learn in the first week: $Z=3 \cdot 24, p<0 \cdot 01$ and $15 \cdot 5 \%(43 / 277)$ responders but $28 \cdot 7 \%(39 / 136)$ non-responders would try to interest a baby of under 3 months with impersonal input only: $Z=3 \cdot 10, p<0.01$.

Fathers-Altogether $63.6 \%(110 / 173)$ responders but $78 \cdot 3 \%$ (54/69) non-responders had previously fed a baby: $Z=2.21, p<0.05$ and $72 \cdot 9 \%(124 / 170)$ responders but $88.6 \%(62 / 70)$ non-responders expected a baby to react to the sound of a slammed door: $Z=2 \cdot 47, p<0.05$. Expectations of response to the mother's voice or heartbeat showed no significant difference between the two groups.

\section{Discussion}

In our technological society parents may know more about the equipment available to save neonatal life than they do about a baby's own innate abilities. Thus over half the parents surveyed agreed with the proposition that 'babies under six weeks old just feed, sleep, cry or fill their nappies'. Although many of their other answers showed more insight, a worrying cohort indicated that this could be their serious opinion.

\section{ANTENATAL IGNORANCE}

For at least $13 \%$ of parents to expect babies of 1 week old neither to enjoy looking at faces or shapes nor to enjoy conversation (table 2) means that they could miss the best period to start mutual early attachment. ${ }^{11}$ For their babies rejected overtures could provoke fretfulness or fussiness during feeds, which would normally offer such golden opportunities for face to face interaction. ${ }^{12}$ Alternatively, babies may stop trying to interact and become withdrawn, feed badly, then fail to thrive. Either way, they are emotionally deprived and could become intellectually delayed, particularly if their parents think them to be unteachable before 3 months of age. Bored babies may cry but then be thought of as naughty. Instead of empathy this can provoke antipathy with the risk of physical abuse to follow. ${ }^{13}$

\section{POSTNATAL OBSERVATION}

In contrast, parents who had expected visual and auditory responses antenatally were significantly more likely to find them postnatally, reporting their baby's attentiveness, bodily movement, mouthing, or other evidence of responsiveness. A third commented on this within the first week of life. Even a mother without such anticipation noticed on her baby's first day how 'She gazed at me with rapt attention and her eyes followed me when I moved'.

There was no correlation between the timing of smiles expected antenatally and witnessed postnatally. Those who claimed early smiles could sound apologetic: 'It was a real smile, the health visitor saw it'. That the average postnatal observation of smiling was 4.4 weeks, not the 6 weeks forecast by about half the antenatal parents and most text books, indicates that young babies themselves can contribute to a revision of opinion. By 3 months of age most were no longer thought to cry from naughtiness, though presumably it was their own preoccupation with the physical aspects of care that tended to make parents now overlook the possibility of a baby's emotionally induced distress.

\section{THE IMPORTANCE OF FATHERS}

It was encouraging that $90 \%$ fathers were present at delivery and that high $\mathbf{P}$ scores and RR scores were so closely associated (table $5 b$ ). Past concentration on mother-infant interaction only has tended to do a disservice to fathers; they should be welcomed to infant welfare clinics and toddler groups as well as to antenatal classes and the labour room. With the apparent exception of agreement about breast feeding, the attitudes and opinions of fathers are usually important to their partners, as the multiparous women in this survey showed by citing them as their 'advisers in chief'. It is, therefore, important to ensure somehow that fathers as well as mothers become correctly informed about early responsiveness from babies (see table 2). As the group of non-responders also showed, both parents need to be told how they prefer personal to mechanical stimulation. Professional advisers might hope to encourage fathers in this but unless from a higher socioeconomic background these men found advice from professionals less acceptable than from their own older generation; few of the fathers 
studied attended antenatal classes. Man to man teaching or more input from the media (including hospital booklets which most read) may be less threatening so more effective.

\section{LEARNING BY EXPERIENCE}

It is often assumed that multiparous women are more likely than others to know about the needs and skills of babies. This was not evident in the areas covered by this study. There was a surprising sameness in the expectations of first time and experienced parents. The mother's antenatal expectation of a baby's innate ability was, for both groups, a more important influence than parity in the correctness of parents' postnatal observations. Ignorance may be reinforced without insight.

It follows that grandparents, from whom young parents often seek advice, may also still need enlightenment. As information about neonatal responsiveness has only been documented in detail during the last two decades, the older generation, unless naturally good at observation, may not stress a baby's need for personal interaction. The myth of windy smiles is still perpetuated, ${ }^{14}$ although admittedly by some professionals as well as by grandmothers: this may explain the reporting of later smiles in babies of experienced parents. (Why babies should be thought to smile with wind when nobody else does remains an unsolved mystery.) The mothers of younger, poorer, early school leavers may well have bottle fed their own babies so could influence their daughters to do the same. Unfortunately, some who consider themselves to be experienced can become unteachable.

\section{RECIPROCAL REGARD, EDUCATION, AND}

\section{DISPOSITION}

Attentive observation of and response to a baby may overthrow antenatal ideas. Thus a mother, adamant that she did not plan to breast feed, reported how the baby had helped to change her mind. 'Almost from birth she was clearly able to focus on my face at close range and smiled at three weeks old'. In watching their baby, from birth, start to learn and to interact her parents had themselves been captivated and instructed. 'Most interesting' to them at 3 months was 'the fact that she tries to carry on a conversation, both with voice, eye contact and gestures and is obviously often "telling" you something'. RR scores were boosted by such warm reporting of mutual rapport between parents and child.

As the assessment was on paper, not in person, the greater fluency of educated minds could itself have affected the scores, though not necessarily so. 'He talks to me and he always smiels, he smiels at everone hue talks to him he is so pleseant' exemplifies sentiment more than scholarship. Better educated mothers tended to have a higher RR score and were more readily attuned to a baby's crying for emotional reasons, as well as being more likely to breast feed. However, breast feeding and sympathy for a baby's emotional distress were also associated with high RR scores among the subgroup of early school leavers (table 5b). Warmth is more a matter of disposition than of a trained mind. Maternal sensitivity was shown particularly by breast feeding mothers with a higher RR score who were more likely to cry with their babies, but educational and social backgrounds were unrelated.

The low score of RRl was commoner among early school leavers. It was associated both with parents' failure to observe early vision in the baby and their having failed to report support from their peers. These mothers were also less likely to cry when their babies cried. Such parents may simply not relate easily or well to many other people, including babies. A poor RR score may thus have wider implications for the stability of a partnership, the perpetuation of social isolation, and the emotional deprivation of children's children. As it may reflect poor parenting it is important to teach and encourage each generation of potential parents to enjoy warmer rapport, not only with babies. That parents with higher RR scores already had warmer personalities tallied with their higher paternal scores and the value that they placed on advice from friends.

\section{POINTERS TO RECIPROCAL REGARD OR ITS ABSENCE: HOW TO PROMOTE IT}

Retrospective review of the antenatal replies of those scoring RR3 shows similar pointers for their subsequent warm interaction with the baby (table 5a). Expressed conversely, regardless of maternal age or parity, parents less likely to have it did not attend antenatal classes, had no interest in breast feeding, and the mothers were likely to have left school early. This compares with at risk groups described by other workers. ${ }^{15-17}$ However, there was more antenatal hope of postnatal warmth if a less educated mother knew that babies enjoy faces and if both parents intended their baby to breast feed.

\section{NON-RESPONDERS}

These parents had shown antenatally a more impersonal attitude to the baby, independent of age, education, or socioeconomic group. Such mothers, regardless of parity, did not expect early learning. Neither did they plan to offer much personal interaction to a 3 month old baby (such as talking, tickling, playing) but instead suggested that babies would like toys, bright lights, record players, or other objects. Their partners, although with a greater previous experience of babies, emphasised their responsiveness to mechanical sounds.

\section{PROMOTION OF RECIPROCAL REGARD}

All parents, including the non-responders, had willingly participated in the antenatal questionnaire and most of the men had intended to be there at the birth. They could equally well have cooperated therefore if personally invited to watch a demonstration of parent-baby interaction in the waiting area. Waiting time could thus have become learning time.

One of the last postnatal questions asked 
parents if their baby had taught them anything and if so, what? Answers ranged from 'What hard work they are' and 'How much patience you need', to indications that, despite any difficulties, mutual reciprocal regard had become high. One fluent mother, recording how her husband shared totally in the baby's care apart from breast feeding ('and that's not his fault') said, 'She's taught me patience and also how it is possible to be absolutely devoted to someone without regard for anything elseI'd lay down my life for her which is quite frightening really'. Such parents are unlikely to be found among child abusers and such babies are likely to thrive, both physically and emotionally.

\section{CONCLUSION}

Being a warm, responsive parent may not come naturally. Even those who do not attend antenatal classes evidently find help from relevant educational booklets, which should therefore be well prepared and widely available. Simple educational input, from primary school onwards, could bring hope of better parent-child attachment. Seeing a baby's face to face interaction, even on video, could encourage belief and behaviour at all ages and in a variety of venues. The widespread use of audiovisual aids is important in an increasingly illiterate society. Ultimately, the best tutorials come within the family circle, but those concerned need first to be attuned.

Those offering antenatal or postnatal care and counsel need to teach not only the mechanics of physical care, including breast feeding, but also the innate potential of babies from birth onwards for engagement in responsive relationships. Some things are better caught than taught. By showing their own enthusiasm and concern, care givers (including informed grandparents) may inspire even experienced parents, together with their other children, to tune in to newborn babies with much greater expectancy than they may otherwise display. Encouraging parents to expect a newborn baby to want early eye to eye contact and conversation and for them to respond to this could be to release warmth and understanding. It could also give the baby a personal opportunity to become the most competent teacher of all.

ED was supported by a grant from the Children's Research Trust, for which we are very grateful. Thanks, too, to the antenatal clinic staff of the North Staffordshire Maternity Hospital, to Dr SA Spencer for advice, and to Lynne Lovekin and Iris Roscoe who processed the words. Best thanks to the parents for their cooperation and to the babies for their tuition. This paper was first presented for his 80th birthday to Professor RS Illingworth at Sheffield Children's Hospital.

1 Curnock D. The senses of the newborn. BMf 1988;299: 1478-9.

2 Goren C, Sarty M, Wu P. Visual following and pattern discrimination of face-like stimuli by newborn infants. Pediatrics 1975;56:544-9.

3 Atkinson J. How does infant vision change in the first three months of life? In: Prechtl HFR, ed. Continuity of neural functions from prenatal to postnatal life. London: Spastics International Medical Publications, 1984.

4 Barrera ME, Maurer D. Recognition of mother's photographed face by the three-month-old-infant. Child Dev 1981;52:714-6.

5 Wolff PH. Observations on the early development of smiling. in: Stone LJ, Smith HT, Murphy LB, eds. The competent infant. 81 .

6 Field T. Neonatal perception of people: maturational and individual differences. In: Field TM, Fox NA, eds. Social perception in infants. New Jersey: Ablex Publishing Corperception in inf
poration, 1985 .

7 MacFarlane A. Olfaction in the development of social preferences in the human neonate. In: Parent-infant interaction. Amsterdam: Elsevier: Ciba Foundation Symposium 33, 1975.

8 Murray $L$. Effects of postnatal depression on infant development: direct studies of early mother-infant interactions. In: Kumar R, Brockington IF, eds. Motherhood and mental illness. London: Wright, 1988:159-90.

9 Lewis C. Becoming a father. Milton Keynes, Philadelphia: Open University Press, 1986.

10 Hintze JL. Number cruncher statistical system. Version 5.0. Utah: Hintze JL, 1987.

11 Klaus MH, Kennell JH. Maternal infant bonding. 2nd Ed. St Louis: CV Mosby, 1982

12 Van Wulfften Palthe T, Hopkins B. Development of the infant's social competence during early face-to-face interaction: a longitudinal study. In: Prechtl HFR, ed. Continuity of neural functions from prenatal to postnatal life. London: of neural functions from prenatal to postnatal life.
Spastics International Medical Publications, 1984.

13 Ounstead C, Oppenheimer R, Lindsay J. Aspects of bonding failure: the psychopathology and psychotherapeutic treatfailure: the psychopathology and psychotherapeutic treat-
ment of families of battered children. Dev Med Child Neurol ment of families

14 Emde RN, Koenig KL. Neonatal smiling and rapid eye movement states. In: Stone LJ, Smith HT, Murphy LB, eds. The competent infant. (No. 52.) London: Tavistock Publications, 1974:282-91.

15 Committee on Child Health Services. Fit for the future. London: HMSO, 1976. (Court report.) (Cmnd 6680.)

16 Neligan GA, Proudham D. Family factors affecting child development. Arch Dis Child 1976;51:853-8.

17 Lewis E. Attendance for antenatal care. BMF 1982;284: 